Short communication

\title{
Transcriptomic effects of the non-steroidal anti-inflammatory drug Ibuprofen in the marine bivalve Mytilus galloprovincialis Lam.
}

\author{
Vera L. Maria ${ }^{\text {a, b }}$, Mónica J.B. Amorim b ${ }^{\text {, }}$ Maria João Bebianno a , Francesco Dondero ${ }^{\text {c, * }}$ \\ a CIMA, Faculty of Science and Technology, University of Algarve, 8005-139 Faro, Portugal \\ b CESAM, Department of Biology, University of Aveiro, 3830-169 Aveiro, Portugal \\ ${ }^{\mathrm{c}}$ Department of Science and Technological Innovation (DISIT), Università del Piemonte Orientale Amedeo Avogadro, 15121 Alessandria, Italy
}

\section{A R T I C L E I N F O}

\section{Article history:}

Received 28 April 2016

Received in revised form 4 May 2016

Accepted 5 May 2016

Available online 10 May 2016

\section{Keywords:}

Inflammation

Mitochondrion

Gene expression

Innate immunity

$\mathrm{NF}-\mathrm{\kappa B}$

Chitinase

GM2 ganglioside activator

\begin{abstract}
A B S T R A C T
The transcriptomic effects of Ibuprofen (IBU) in the digestive gland tissue of Mytilus galloprovincialis Lam. specimens exposed at low environmental concentrations $\left(250 \mathrm{ng} \mathrm{L}^{-1}\right)$ are presented. Using a $1.7 \mathrm{~K}$ feature cDNA microarray along with linear models and empirical Bayes statistical methods 225 differentially expressed genes were identified in mussels treated with IBU across a 15-day period. Transcriptional dynamics were typical of an adaptive response with a peak of gene expression change at day7 (177 features, representing about $11 \%$ of sequences available for analysis) and an almost full recovery at the end of the exposure period. Functional genomics by means of Gene Ontology term analysis unraveled typical mussel stress responses i.e. aminoglycan (chitin) metabolic processes but also more specific effects such as the regulation of NF- $\mathrm{KB}$ transcription factor activity.
\end{abstract}

๑) 2016 Elsevier Ltd. All rights reserved.

\section{Introduction}

Pharmaceutically-active compounds (PhACs) reach the aquatic environment i.e. surface/ground water, rivers, lakes, effluents of wastewater treatment plants and seawater as a result of diverse anthropogenic actions (Richardson and Ternes, 2005). This continuous flow of PhACs poses concerns in terms of the potential toxicological consequences to non-target organisms (Fent et al., 2006). The group of environmental PhACs include pain and fever relieves, anti-inflammatory drugs, antibiotics, blood lipid regulators, beta-blockers, antidepressants, antiepileptics, sex hormones as well as anti-neoplastics and anti-tumor drugs (Gaw et al., 2014; Richardson and Ternes, 2005). Ibuprofen (IBU) is among the most consumed non-prescription medication worldwide (Mestre et al., 2007). It belongs to the class termed non-steroidal anti-inflammatory drugs (NSAIDs) (Mestre et al., 2007). These drugs are used to treat pain, fever and inflammation, mainly acting via the inhibition of the cyclooxygenases (COX), resulting in lower levels of prostaglandins and hence reducing the typical symptoms (Cryer

\footnotetext{
* Corresponding author.

E-mail address: francesco.dondero@uniupo.it (F. Dondero).
}

and Feldman, 1998).

The occurrence of IBU in surface waters ranges from $90 \mathrm{ng} \mathrm{\textrm {L } ^ { - 1 }}$ (river Rhine at Main, Germany) (Ternes, 1998) to $2370 \mathrm{ng} \mathrm{L}^{-1}$ (Tyne estuary, England) (Thomas and Hilton, 2004) and to $2700 \mathrm{ng} \mathrm{L}^{-1}$ in (Anoia river, Spain) (Ferrer et al., 2001). In waste water treatment plant effluent it is easily found at ppm amounts (Pedrouzo et al., 2007). More recently, a comprehensive review on the presence of PhACs in seawater reported a IBU concentration range of 0.01-2370 ng L ${ }^{-1}$ (Gaw et al., 2014).

IBU effects in aquatic invertebrates was mainly assessed for sublethal toxicity using either common ecotoxicological or biomarker approaches (Contardo-Jara et al., 2011; Ericson et al., 2010; Fabbri et al., 2014; Gonzalez-Rey and Bebianno, 2011, 2012; Matozzo et al., 2012; Mezzelani et al., 2016; Parolini et al., 2009, 2011a, 2011b; Serrano et al., 2015). Nowadays, new techniques such as transcriptomics offer a holistic viewpoint of the biological response to environmental stressors in aquatic organisms (Waters and Foster, 2004; Milan et al., 2013a). This technique provides a systems-based unbiased approach for the development of biomarkers able to respond to low realistic (environmental) contaminant concentrations. A transcriptomic assessment was successfully applied in classical cellular model systems to evaluate possible anticancer activity or cytotoxicity of IBU and/or similar drugs 
(Bonelli et al., 2011; Herpers et al., 2016; John-Aryankalayil et al., 2009). In aquatic animals and in particular in marine ones, the information is scarce. Global transcriptomic responses were studied in Daphnia magna (Heckmann et al., 2008) and clam Ruditapes philippinarum (Milan et al., 2013b) exposed to IBU. In general, however, the aforementioned studies did not considered the effects at low realistic concentrations.

The aim of the present study is to determine the molecular pathways involved in IBU response in a non-target organism challenged with environmentally relevant amounts of the drug; thus infer the action mode and the possible implications on the individual performance and ecological risk assessment. To this end, time-series gene expression analysis was carried out in the digestive gland of the marine mussel Mytilus galloprovincialis exposed to $250 \mathrm{ng} \mathrm{L}^{-1}$ IBU across a 15-day period. Transcriptomics was based on the custom $1.7 \mathrm{~K}$ cDNA mussel microarray (Mytarray V1.1) (Venier et al., 2006; Dondero et al., 2011).

\section{Materials and methods}

\subsection{Chemicals}

Ibuprofen [2-(4-isobutylphenyl) propanoic acid] CAS number 15687-27-1 was purchased from Sigma-Aldrich (Germany).

\subsection{Experimental design}

Mytilus galloprovincialis (length size: $54 \pm 2 \mathrm{~mm}$ ) were collected at low tide in Ria Formosa Lagoon (Portugal) and acclimated in filtered (200 $\mu \mathrm{m}$ mesh) aerated seawater for 7 days, under laboratory conditions in 8 tanks of $25 \mathrm{~L}$ each at a density of 1 animal per liter. After the acclimation period, some specimens were dissected removing gonads and digestive glands. The latter were immediately flash-frozen in liquid nitrogen and stored at $-80{ }^{\circ} \mathrm{C}$ until analysis while gonads were microscopically inspected for sex determination. This group of samples was set as day- 0 (control). The remaining specimens were equally divided into 28 tanks, and then exposed in four independent experimental setups either to natural seawater (control) or $250 \mathrm{ng} \mathrm{L}^{-1}$ IBU during 3, 7 and 15 days in aquaria. For each condition, digestive gland from 10 to 20 animals were dissected, flash frozen in liquid nitrogen and kept at $-80{ }^{\circ} \mathrm{C}$ until further analysis. Microscopic inspection of gonads was performed in order to determine sex and eliminate bias in gene expression profiles (Dondero et al., 2011; Banni et al., 2011). For this study only females were considered. Media and the respective drug concentrations were renewed every 2 days. The selected IBU concentration was sub-lethal in mussels (data not shown) and within environmentally realistic levels in marine waters as previously reported (Gaw et al., 2014). Seawater abiotic parameters, namely temperature $\left[19.3 \pm 2{ }^{\circ} \mathrm{C}\right]$, salinity $[(34.2 \pm 2], \mathrm{pH}[(7.8 \pm 0.20]$, and dissolved oxygen $(7.2 \pm 0.6)$ were measured [average \pm standard deviation (SD)] throughout the experiment prior to and following the water exchange.

\subsection{Microarray analysis and statistics}

Transcriptomic analysis was performed using the Mytarray V1.1 platform. This array encompasses 3' cDNA probes representing 1673 independent mussel sequences obtained from unbiased M. galloprovincialis tissues-specific normalized cDNA libraries, plus positive and negative control features. A detailed description of the sequence catalogue and other information of the array construction can be found in Venier et al. $(2003,2006)$. Total RNA was extracted from the digestive glands as previously described (Dondero et al., 2005). The procedures for dual color competitive microarray hybridization using the Mytarray V1.1 (Venier et al., 2006; Dondero et al., 2011) were carried out as previously described using Су3/Су5 labelled cDNA probes (Banni et al., 2011), starting from $5 \mu \mathrm{g}$ total RNA. For the assessment of transcriptomic effects, a loop design was employed made of contrasts between two variable classes, i.e."time" $(0,3,7,15$ days) and "treatment" (drug exposed, notexposed) for a total of 28 arrays (Fig. 1). This scheme encompassed 4 biological replicates and 4 technical replicates for all samples except T0 for which only two biological replicates were used. The dye swap procedure was used to suppress dye effects. Each biological replicate consisted of equal amounts of total RNA pooled from 4 to 6 females specimens collected in a single independent tank.

Statistical analysis of microarray data was performed in $\mathrm{R}$ using the package Linear Model for Microarray Analysis (LIMMA) (Ritchie et al., 2015). Benjamini \& Hochberg's (BH) false discovery rate (FDR) correction was used (Benjamini and Hochberg, 1995). Expression values, M, refer as to the $\log 2$ ratio between mRNA level of exposed vs not-exposed sample at each temporal condition.

Hierarchical clustering was carried out using the Genesis software (Sturn et al., 2002) in combination with the Euclidean distance algorithm Dot Product (Brown et al., 2000).

Functional analysis was performed using Gene Ontology (GO) annotation and the universal platform Blast2GO (Conesa et al., 2005). GO terms over-representation analysis was implemented within the Blast2GO platform through a hypergeometric statistics. BH-FDR correction was applied on over-represented GO terms at $p<0.05$.

\subsection{Quantitative PCR (QPCR) analysis}

Total RNA (0.50-0.75 $\mu \mathrm{g})$ from control or exposed mussels $(n=6)$ were reverse transcribed in a $20 \mu \mathrm{l}$ reaction mixture made of $250 \mathrm{ng}$ random hexamers (Invitrogen ${ }^{\mathrm{TM}}$, Thermo Scientifics, USA), $200 \mathrm{U}$ M-MuLV H- reverse transcriptase (Fermentas, Vilnius, LI), $1.0 \mathrm{mM}$ dNTPs (Roche) and 1X M-MulV enzyme buffer as described in Dondero et al. (2005). Five (5) ng of RNA equivalent reversetranscribed cDNA were amplified in a real time PCR apparatus (CFX384, Bio-Rad) using the "iQ multiplex powermix" (Bio-Rad) in duplex or triplex TAQMAN reactions, in the presence of $0.2 \mu \mathrm{M}$ each forward and reverse primer and $0.1 \mu \mathrm{M}$ each dual-labelled probe. The thermal protocol was as follows: $30 \mathrm{~s}$ at $95^{\circ} \mathrm{C}$, followed by 40 cycles $\left(10 \mathrm{~s}\right.$ at $95{ }^{\circ} \mathrm{C}, 20 \mathrm{~s}$ at $\left.60^{\circ} \mathrm{C}\right)$. Primer, probes sequences and PCR conditions for chitinase AJ624637, AJ625569, AJ624093, AJ625051 and GM2 activator protein AJ624405, were as described in Dondero et al. (2011). The analysis of the p63-73 (AJ625243) relative mRNA abundances was carried out as previously reported using the Sybr-Green chemistry (Banni et al., 2009). The same conditions were also used to analyze the TNF receptor F19 (TNFRSF19, AJ624165) whose primers were designed using the Beacon Designer V. 3.0 software (Premier Bio-soft International, Inc.) (Table 1).

Gene expression data were expressed as group mean and geometrically normalized on four invariant mussel sequences: $18 \mathrm{~S}$ rRNA (L33452), an actin (ACT) isotype (AF157491), the ribosomal protein L27 (AJ625928) and glyceraldehyde 3-phosphate dehydrogenase (G3PDH) (AJ625142) (for sequence details see Table 1). Oligonucleotides and Taqman dual-labelled probes were manufactured by MWG-Biotech (Germany).

Statistical computation and analysis of QPCR data were carried out using the REST and REST-mcs software using a threshold cycle reallocation randomization test at $\mathrm{p}<0.05$ (Pfaffl, 2001; 2002). 


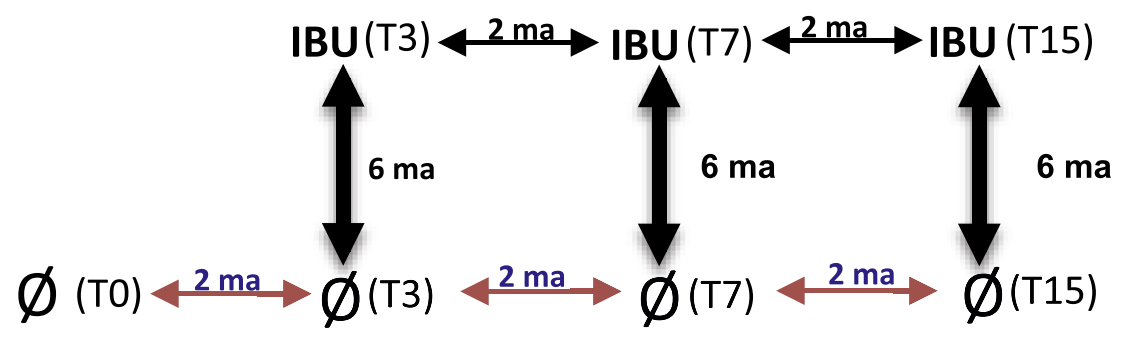

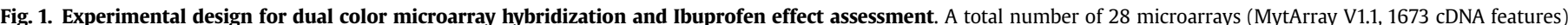

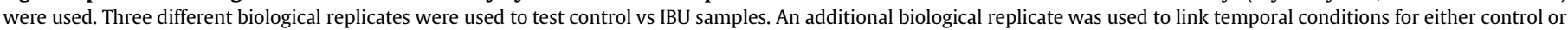

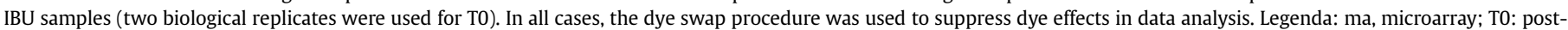

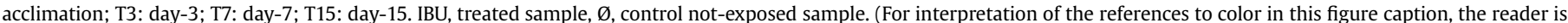
referred to the web version of this article.)

Table 1

QPCR primers and probes.

\begin{tabular}{|c|c|c|c|c|}
\hline Housekeeping genes & Reporter dye & Probe & Sense primer & Antisense primer \\
\hline G3PDH (AJ625142) & CY5 & CTGCTCCTGTTGTCTCCACGGAAGTCTT & TCTGAGGGTCCAATGAAGGGTG & GAGCGATGCCAGCTTTGGC \\
\hline 18S (L33452) & TEXAS RED & ACCACATCCAAGGAAGGCAGCAGGC & CGGAGAGGAGCATGAGAAAC & CGTGCCAGGAGTGGGTAATTT \\
\hline ACT (AF157491) & HEX & ACGCCAACACCGTCTTGTCTGGTGG & GTGTGATGTCGATATCCGTAAGGA & GCTTGGAGCAAGTGCTGTGA \\
\hline L27 (AJ625928) & FAM & TGCGCCATTCAGCACAAGAACTACCT & AAGCCATGGGCAAATTTATGAAAA & TTTACAATGACTGCTTTACGACCT \\
\hline Target genes & & Probe & Sense primer & Antisense primer \\
\hline TNFR19F (AJ624165) & SYBR Green I & n.a. & CCGAAGCCAACAGGACATTT & TGATGGCACTTAGAACAAAATCC \\
\hline
\end{tabular}

Sequences are reported in the $5^{\prime}-3^{\prime}$ format; n.a., not applicable in SYBR Green I analysis.

\section{Results}

\subsection{IBU transcriptomic effects across time}

Using a 1.7-K feature cDNA microarray along with linear models and empirical Bayes statistical methods transcriptome profiles were generated for the digestive gland of mussels exposed to environmental concentrations of IBU (250 $\left.\mathrm{ng} \mathrm{L}^{-1}\right)$ across a 15-day exposure period (see Fig. 1 for experimental design details). Microarray analysis yielded distinct patterns for 225 differentially expressed genes (DEGs) (Table 2; Supplementary Data Tables S1-S3), representing $13.4 \%$ of sequences available for the analysis (1673 features in the V1.1, Dondero et al., 2011). DEGs were numerically distributed according to a bell shape curve (Table 2). Relative mRNA abundances increased for the majority (81\%) of genes in the beginning of the exposure (day-3) (Supplementary Data Table S1), conversely decreased in the middle of the exposure (day-7) (Supplementary Data Table S2) and turned back to nearly control values at the end of the exposure. At day-15, in fact, only one statistically significant DEG could be identified i.e. GM2 activator protein (AJ624405) whose expression was up-regulated (Supplementary Data Table S3).

Average Dot Product clustering of mRNA relative abundances

Table 2

Number of differentially expressed genes (DEGs) in M. galloprovincialis digestive gland tissue exposed to IBU.

\begin{tabular}{lclc}
\hline Time $(\mathrm{d})$ & Total $(\#)$ & Up-regulated $(\#)$ & Down-regulated $(\#)$ \\
\hline 3 & 73 & 69 & 14 \\
7 & 177 & 53 & 124 \\
15 & 1 & 1 & 0 \\
\hline
\end{tabular}

Shown are number of DEGs founds for the effects of IBU $(p<0.05$ BH-FRD correction). allowed a systematic dissection of gene expression patters into three main clusters (Fig. 2). Cluster 1 encompasses genes showing a U-shape profile across time; Cluster 2 genes were down regulated all along the time-course whilst Cluster 3 genes display a bell-shape trend with up-regulation at day-7 (Fig. 2).

Gene Ontology terms enrichment analysis was carried out to unravel gene functions and biological processes statistically associated to each cluster (see Supplementary Data Table S4 for full details on the analysis output). The REVIGO tool was used to summarize GO terms according to their semantic distance (Supek et al., 2011), highlighting the most relevant and non-redundant features. Table 3 shows the putative biological processes occurring in digestive gland cells for the effects of the anti-inflammatory drug. Cluster 1 basically accounts for amino-glycan (i.e. chitin) metabolic processes; Cluster 2 for transcription factor regulation activity involving NF- $\kappa \mathrm{B}$; Cluster 3 for mitochondrial organization and biogenesis.

\subsection{Quantitative PCR analysis}

Real time quantitative PCR was carried out to confirm some microarray data (Fig. 3). For IBU day-7 exposure (where the highest amount of DEGs was found), the expression of different chitinase genes (AJ625051, AJ624637, AJ624093, AJ625569), the p63-73 (AJ625243) and a TNF receptor F19 gene (TNFRSF19, AJ624165) were assessed and the expression levels were down-regulated. For 15-day IBU exposure we could confirm the adaptive response of chitinases (no changes with respect to the control level) and a strong over-expression of the GM2 activator protein gene AJ624405. In general, QPCR data rendered a good relationship between microarray and QPCR relative mRNA abundance levels, demonstrating the reliability of the cDNA microarray data (Fig. 3). 


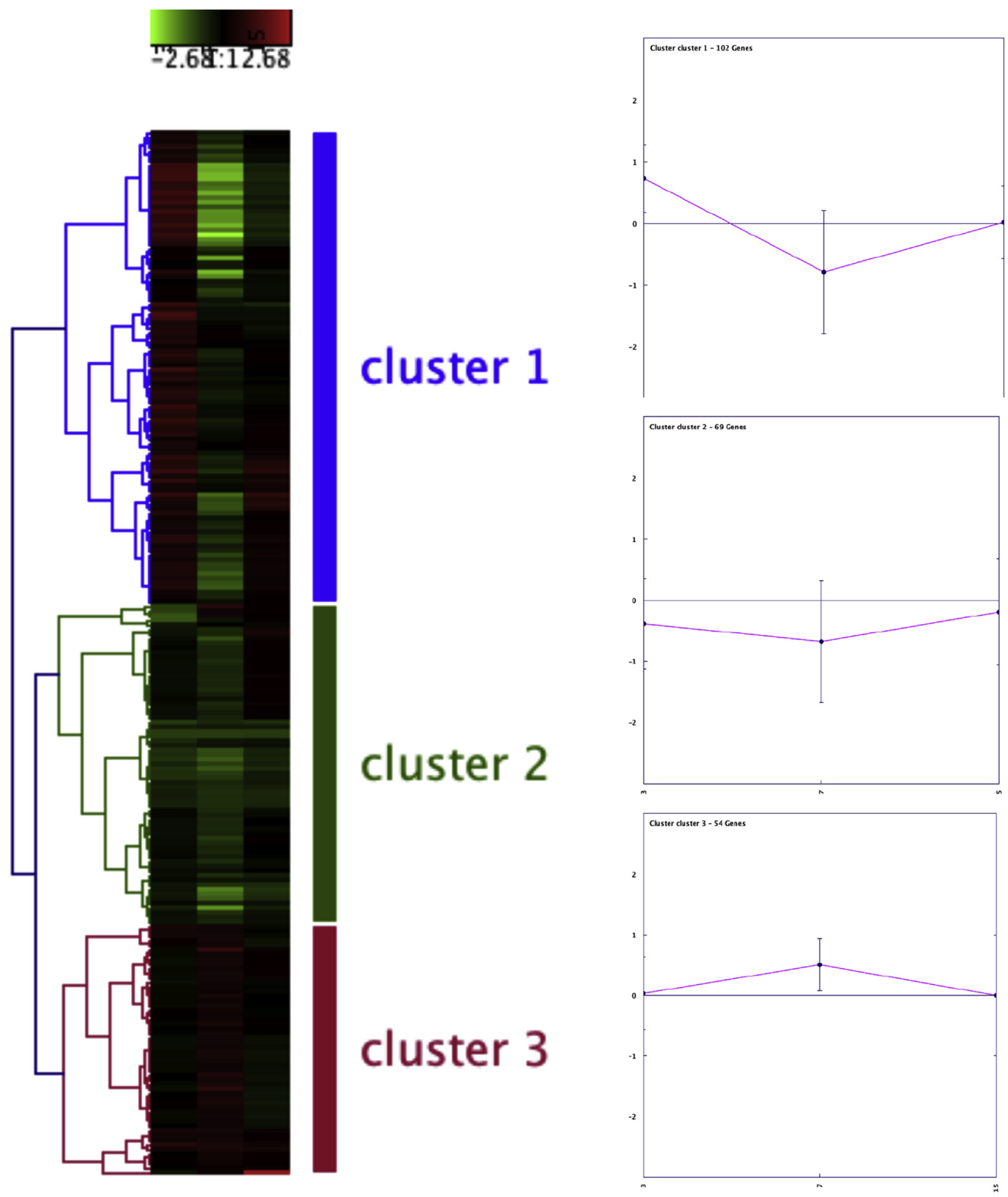

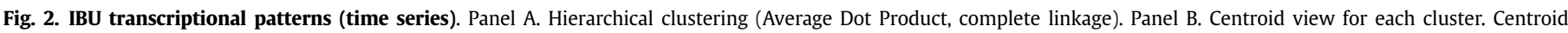
represents the arithmetic average expression value (M) at each condition.

\section{Discussion}

\subsection{Molecular adaptive response to IBU}

There is growing body of evidence that pharmaceutical active compounds, such as NSAIDs, represent emerging contaminants in marine ecosystems (Gaw et al., 2014). The ecological risk of this class of chemicals is higher than that of common environmental pollutants since these drugs were specifically formulated and/or selected to induce biological effects at very low doses. Recent data showed that in the marine mussel (M. galloprovincialis Lam.) submicromolar concentrations of IBU are quickly bio-accumulated into soft tissues and can be easily found at ppb amounts in tissues of wild animals sampled in coastal areas during the touristic season (Mezzelani et al., 2016). These facts point to the necessity to test PhACs effects on non-target species at environmentally 
Table 3

Functional genomics of IBU modulated genes (GO terms over-representation analysis).

\begin{tabular}{|c|c|c|c|c|}
\hline GO term_ID & Description & Cluster & Frequency & Gene \\
\hline GO:1901564 & organonitrogen compound metabolic process & 1 & $19.57 \%$ & $\begin{array}{l}\text { AJ624093, AJ625051, AJ625569, AJ624667, AJ625778, AJ624637, AJ623376, AJ625903, } \\
\text { AJ624419, AJ624495, AJ625276, AJ516903, AJ625832, AJ624501 }\end{array}$ \\
\hline GO:1901135 & carbohydrate derivative metabolic process & 1 & $11.65 \%$ & $\begin{array}{l}\text { AJ625569, AJ625778, AJ624093, AJ624637, AJ623376, AJ625051, AJ625903, AJ624419, } \\
\text { AJ624495, AJ625276, AJ516903 }\end{array}$ \\
\hline GO:1901575 & organic substance catabolic process & 1 & $9.32 \%$ & $\begin{array}{l}\text { AJ625569, AJ625778, AJ624093, AJ624637, AJ623376, AJ625051, AJ625903, AJ624509, } \\
\text { AJ624495 }\end{array}$ \\
\hline GO:0006022 & aminoglycan metabolic process & 1 & $1.10 \%$ & $\begin{array}{l}\text { AJ625569, AJ625778, AJ624093, AJ624637, AJ623376, AJ625051, AJ625903, AJ624419, } \\
\text { AJ625276, AJ516903 }\end{array}$ \\
\hline GO:0006040 & amino sugar metabolic process & 1 & $0.39 \%$ & $\begin{array}{l}\text { AJ625569, AJ625778, AJ624093, AJ624637, AJ623376, AJ625051, AJ624419, AJ625276, } \\
\text { AJ516903 }\end{array}$ \\
\hline GO:0006026 & aminoglycan catabolic process & 1 & $0.24 \%$ & AJ625569, AJ625778, AJ624093, AJ624637, AJ625051 \\
\hline GO:1901071 & $\begin{array}{l}\text { glucosamine-containing compound metabolic } \\
\text { process }\end{array}$ & 1 & $0.13 \%$ & $\begin{array}{l}\text { AJ625569, AJ625778, AJ624093, AJ624637, AJ623376, AJ625051, AJ624419, AJ625276, } \\
\text { AJ516903 }\end{array}$ \\
\hline GO:0044093 & positive regulation of molecular function & 2 & $0.23 \%$ & AJ624130, AJ625043, AJ624383, AJ624165 \\
\hline GO:0051090 & $\begin{array}{l}\text { regulation of sequence-specific DNA binding } \\
\text { transcription factor activity }\end{array}$ & 2 & $0.02 \%$ & AJ624130, AJ625043, AJ624165 \\
\hline GO:0051091 & $\begin{array}{l}\text { positive regulation of sequence-specific DNA } \\
\text { binding transcription factor activity }\end{array}$ & 2 & $0.01 \%$ & AJ624130, AJ625043, AJ624165 \\
\hline GO:0051092 & $\begin{array}{l}\text { positive regulation of NF-kappaB transcription } \\
\text { factor activity }\end{array}$ & 2 & $0.01 \%$ & AJ624130, AJ625043, AJ624165 \\
\hline GO:0007005 & mitochondrion organization & 3 & $0.05 \%$ & AY484747, AY484747, AY484747, AJ625490 \\
\hline
\end{tabular}

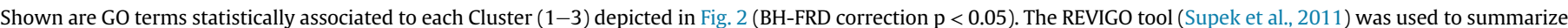

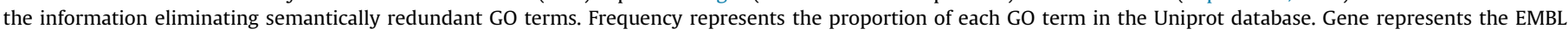
accession number of mussel sequences associated to each specific GO term.

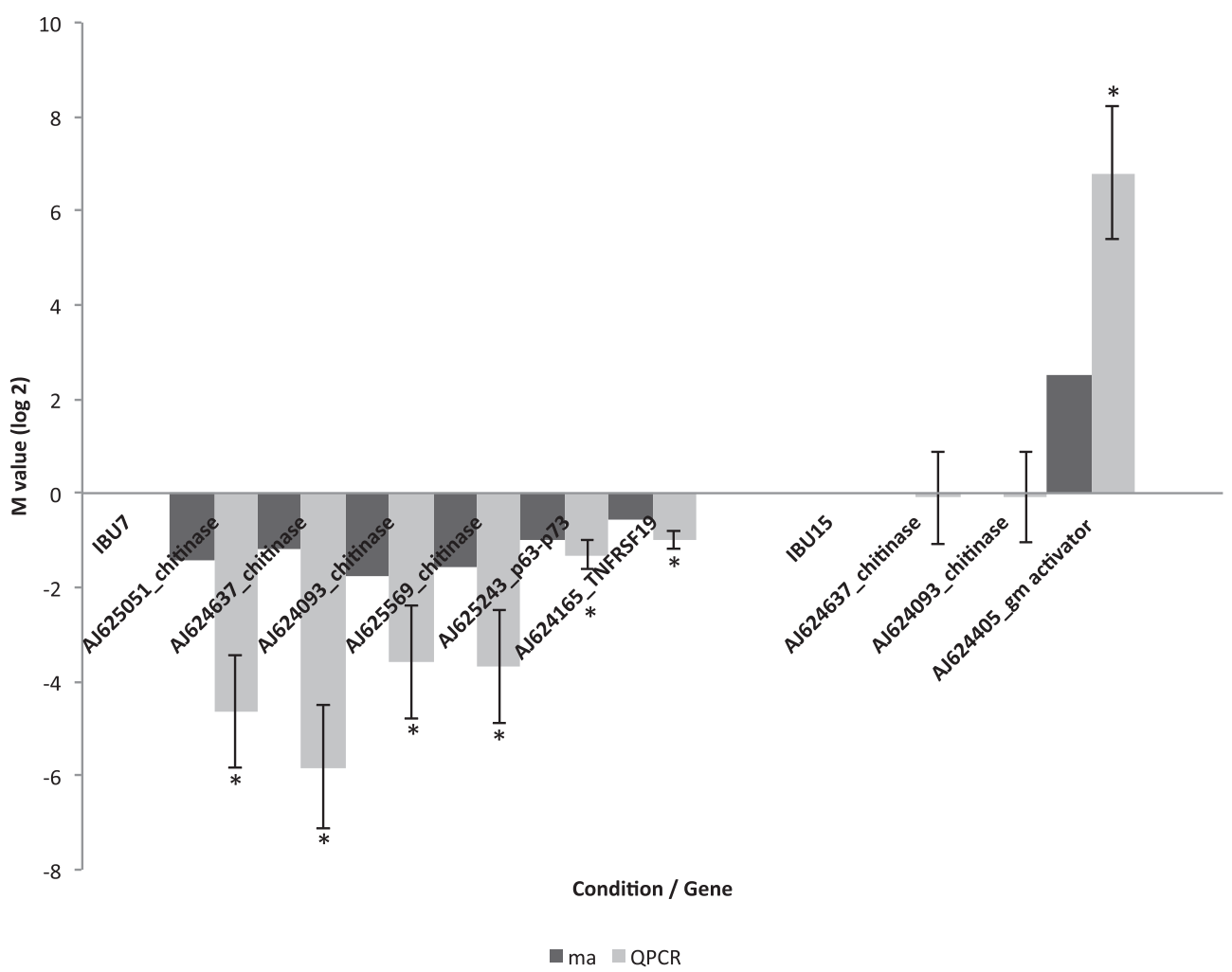

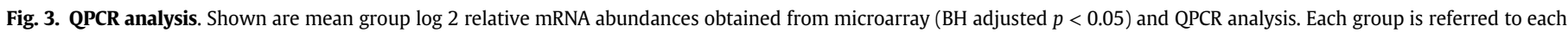
specific control (not-exposed sample). ${ }^{*} p<0.05(n=6)$, threshold cycle reallocation randomization test according to Pfaffl et al. (2001, 2002).

relevant concentrations. High-throughput transcriptomics represents a discovery-based approach to predict the action mode of noxious chemicals in a sensitive and specific way. To the best of our knowledge, this work represents the first application of microarrays to characterize low-dose effects of NSAIDs in marine bivalves. Our present study allowed capturing 225 different DEGs with a high statistical confidence (BH FDR correction, $p<0.05$ ).
Molecular responses to IBU peaked at day-7 where the highest number of DEGs was identified (Table 2). In this case, Clusters 1 (basically accounts for amino-glycan (i.e. chitin) metabolic processes) and 2 (regulation activity involving NF- $\kappa \mathrm{B}$ ) clearly differed from Cluster 3 (mitochondrial organization and biogenesis) for their average expression (centroid) values with negative centroid values for Clusters 1 (trend of down-regulation) and 2 (trend of 
down-regulation) and positive for Cluster 3 (trend of upregulation). Cluster 1 and 2 differed also for their centroid values at day-3 (for more details see Fig. 2, panel B). However, this molecular dynamics was transient and the expression levels returned nearly to initial values (day- 0 ) at the end of the exposure period in all clusters (Fig. 2, Panel B). Microarray analysis identified a single DEG at 15-day of IBU exposure (Table 2, Table S3) and QPCR confirmed (Fig. 3). In systems biology this pattern is referred to as a molecular adaptive response and indicates system resilience (Gasch et al., 2000). Adaptation through epigenetics, i.e. gene expression changes, was described in microorganisms exposed to a variety of environmental stimuli. In the baking yeast (Gasch et al., 2000) and Escherichia coli (Jozefczuk et al., 2010) it was demonstrated that system perturbation by either diauxic shift, oxidants, temperature or osmotic shock determined an adaptive molecular response whose duration in time depends on the intensity of the initial stimulus. The system adapts and survives only if this recovery phase is terminated in a period of time compatible with the organism life-cycle. It is worth noting that results were also similar for what concerns the type of genes involved in system adaptation. In fact, the majority of DEGs were common independently on the type of stress and only a marginal fraction (e.g. 10\%) was treatmentspecific. Transcriptomics allowing the simultaneous evaluation of thousands variables on the same hierarchical order of information (i.e. mRNA level) seems to represent the ideal approach to investigate molecular dynamics and adaptive responses to environmental stressors also in metazoans and, in this specific case, marine bivalves. Despite the limited amount of information available on the micro-chip used in the present study, that bears only 1673 sequences (Venier et al., 2003, 2006) our gene expression analysis demonstrates that this is a sensitive tool to detect the effects of IBU at low environmental concentration found in seawater (Gaw et al., 2014). It should be pointed out, however, that the investigation of low level NSAID effects may be hindered by the transient nature of gene expression profiles. This consideration will be particularly important in future field assessment using wild animals whose life history is unknown. We, therefore, do recommend the implementation of good biomonitoring practices employing caged mussels and transplantation experiments (Dondero and Calisi, 2015; Gorbi et al., 2008). Further research using larger array (Boatti et al., 2012) and/or RNA-seq approach (Moreira et al., 2015) will be required to identify candidate biomarkers of exposure to IBU and other NSAIDs. The possible use of specific antibodies against NF- $\kappa$ B peptides (Canesi et al., 2006) will be envisaged in further investigations, since protein response is usually more robust.

\subsection{Qualitative features of IBU adaptive responses: the involvement of $N F-\kappa B$ pathway}

Transcriptomics has the potential to convert quantitative expression data into qualitative information on the mode of action of noxious chemicals as well as pharmaceuticals active compounds. To this end, we used Gene Ontology (GO) (Ashburner et al., 2000) to carry out functional genomics analysis on the 225 DEGs found for the effects of IBU in the digestive tissue of marine mussels. Overrepresented GO terms were assigned to each cluster gene set (Supplementary Data Table S4 and Table 3). It is worth noting that Cluster 2 genes are statistically associated to the NF- $\kappa B$ pathway and that inhibition of NF- $\kappa \mathrm{B}$ activation is a critical component of the pharmacological mode of action of IBU (Tegeder et al., 2001) along with the more established cyclooxygenase (COX) inhibition (Cryer and Feldman, 1998; Scheuren et al., 1998). NF-кB family is a group of heterodimeric transcription factors found in almost all animal cell types and involved in cellular responses to stress, cytokines, free radicals, ultraviolet irradiation and bacterial or viral antigens (Oeckinghaus et al., 2011). In mammals there are five component proteins: RelA (p65), RelB and c-Rel, and the precursor

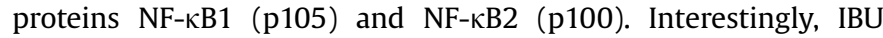
exposure (7-day) increased the mRNA level of a genuine NF- $\kappa B$ gene, i.e. the Rel homologue protein (AJ623779) (Supplementary Data Table S2).

$\mathrm{NF}-\kappa \mathrm{B}$ plays a key role in regulating the immune response and inflammation. Its activation is mediated by integral membrane proteins belonging to the TNF receptor family (TNFR) like the TNFRSF19 (AJ624165) gene found in the present study whose relative mRNA abundance decreased in tissues from IBU exposed animals (Supplementary Data Table S2, Fig. 3). TNFR activation leads to a very complex signaling cascade pathway culminating with degradation of an inhibitory protein and further NF- $\kappa B$ translocation into the nucleus (Oeckinghaus et al., 2011). Functional genomic analysis identified two more genes associated with the NF- $\kappa$ B pathway, namely AJ624130 and AJ625043 whose expression levels were down-regulated at 7 days of IBU exposure (Supplementary Data Table S2). Both have sequence homology with members of the inflammasome protein complex, the NLR (nucleotide-binding, leucine-rich repeat-containing) family (Davis et al., 2011) whose activation is often induced by NF- $\kappa B$ (Bauernfeind et al., 2009). Although inflammasome NLR proteins generally do not interact directly with $N F-\kappa B$ signaling, some members can positively or negatively modulate NF- $\kappa B$ activity depending on the specific stimulus (Schneider et al., 2012). A gene responsible for $\mathrm{NRL} / \mathrm{NF}-\kappa \mathrm{B}$ crosstalk is IAP2. Interestingly, microarray results identified also an IPA2 homologue (AJ624156) whose expression was up-regulated at day-7 of IBU exposure (Supplementary Data Table S2). IAP2 acts as an E3 ubiquitin-protein ligase regulating the activity of NRL proteins such as Nod-like receptors (Abbott et al., 2007). Furthermore, IAP2 is a central modulator of NF- $\kappa B$ acting either positively or negatively respectively through the canonical or non-canonical signaling pathway culminating with NF$\kappa \mathrm{B}$ translocation in the nucleus (Oeckinghaus et al., 2011). A second E3 ubiquitin-protein ligase gene with similar expression level of IAP2 was also found in our dataset (AJ623726, Supplementary Data Table S2). These data are in accordance with those found in tissues of the marine clam Ruditapes philippinarum challenged with much higher IBU concentrations (1 mg/L). Milan et al. (2013b) using a $15 \mathrm{~K}$ oligonucleotide microarray identified three different E3 ubiquitinprotein ligase (IAP) genes belonging to the Nod-like signaling pathway as well as a genuine NF- $\kappa$ B gene $(\mathrm{NF}-\kappa \mathrm{B} 1$ ) whose expression level increased. Furthermore, our present study and that by Milan et al. (2013b) reveal interesting common patterns in the modulation of cancer genes. The latter feature deserves particular attention since the NF- $\mathrm{BB}$ and apoptosis pathways are tightly correlated (Karin and Greten, 2005; Sokolova, 2009). In IBU treated mussels caspase-7 (AJ625490, Table S2) -that is activated through NRL-mediated caspase-1 activation (Lamkanfi and Kanneganti, 2010)- was up-regulated at day-7. The b-cell translocation gene anti-proliferative homologue (btg-1) that can positively regulate the NF- $\kappa$ B pathway (Cho et al., 2005) was down-regulated in IBU exposed mussels. The delta-N p63-p73 gene (AJ625243) p53 family member -a transcription factor lacking the transactivation domain and with yet unknown function in Mytilus sp. (Banni et al., 2009; Muttray et al., 2007) -was also down-regulated at day-3 and day7 (Supplementary Data Table S1-S2; Fig. 3). In contrast, the tumor suppressor Lethal Giant Larvae homologue 2 gene (Peng et al., 2000), was over-expressed at day-7. This molecular response is consistent with anti-proliferative and pro-apoptotic effects of IBU, as previously described (Bonelli et al., 2011; Dey et al., 2008).

Summarizing, present results are consistent with previous hypothesis of a conserved scheme of NF- $\kappa \mathrm{B}$ gene organization and regulation (Canesi et al., 2006; Montagnani et al., 2004, 2008; 
Sokolova, 2009), as well as a similar cellular target for IBU, NF-кB. These findings point to the need to further investigate whether in a real ecological context the observed transient response may give rise to aberrant interactions with normal NF- $\mathrm{BB}$ signaling, in response to a changing environment, viz. food availability, bacterial infection, physical and chemical stress, etc. To this end, it would be very useful to study the effects of multiple stress challenge and put in relation NF- $\kappa \mathrm{B}$ signaling activity with individual performance of animals (Kearney et al., 2010). Since previous reports in Mytilus sp. suggest the possibility to test NF- $\kappa \mathrm{B}$ pathway activation using commercially available antibodies (Canesi et al., 2006), highthroughput microarray data should be combined with more mechanistic evidence arising from NF- $\kappa \mathrm{B}$ interactomics.

Another feature highlighted by the functional genomics analysis concerns the effects of low IBU doses on genes related to mitochondrion organization (Table 3) (as three mitochondrial RNA genes and the aforementioned caspase 7 were up-regulated at day7, see Supplementary Data Table S2). This might reflect mitochondrial biogenesis to cope for mitochondrial membrane depolarization by NSAIDs that ultimately can activate caspase 7 by means of the apoptosis-inducing factor (AIF) (Lakhani et al., 2006). This hypothesis seems compatible with the oxidative burst and antioxidant system response observed in same mussel tissues by Gonzalez-Rey and Bebianno (2012), but further data are needed to shed light on the occurrence of this pathway. It should be pointed out, however, that from our microarray data on mussels and those on clams (Milan et al., 2013b), no evidence emerges for the occurrence of a genuine anti-oxidant molecular response. This is in apparent contrast to what was observed in human gastric adenocarcinoma cells (Bonelli et al., 2011) where cytochrome family transcripts and ROS levels were induced by p450 redox cycling.

\subsection{Modulation of chitinase and GM2 activator protein genes}

A remarkable finding is the involvement of chitinases and GM2 activator genes in response to IBU. These genes dominated Cluster 1 (Fig. 2, Table 3) and in Mytilus sp. they seem to have a role in general stress response. Several toxic treatments such as metals and pesticides as well as hormones were shown to regulate the expression levels of these genes (Dondero et al., 2010, 2011; Canesi et al., 2011). Chitinase expression was severely down-regulated by IBU at day-7 (Fig. 3). In mussels these genes are up-regulated during energy store accumulation (Banni et al., 2011) and therefore may serve in basic metabolic functions (Birkbecka and McHenery, 1984). Microarray data in clam supports the hypothesis of a metabolic stress in response to IBU (Milan et al., 2013b), however, an implication of chitinase on the innate immune system cannot be excluded since aminoglycans (i.e. chitin) are precursors of potent bacterial antigens (Badariotti et al., 2007). GM2 activator is a class of a lysosomal protein involved in beta-hexosaminidase A activation. These genes have been associated to fatal lipid disorder in the nervous system of humans (Mahuran, 1998), however their functions remain practically unknown. In the mussel digestive gland tissue there are at least two homologs of GM2 activator whose expression changes have been associated with the metal-induced lysosomal hyperlipidosis (Dondero et al., 2011). The present results on IBU effects showed up-regulation of AJ624495 at day-3 (Supplementary Data Table S1) and the up-regulation of AJ624405 at day-15 (Supplementary Data Table S3, Fig. 3). In general, these results indicate that chitinase and GM-activator represent promising candidate gene for general stress biomarkers. Further research is needed to clarify their expression and functional involvement in response to chemical stress.

\section{Conclusions}

Our results demonstrated that environmental amounts of IBU could transiently modulate the NF- $\kappa \mathrm{B}$ gene pathway in Mytilus sp. tissues, thus indicating specific pharmacological effects on nontarget organisms. Moreover, Chitinase and GM2 activator protein genes were confirmed as novel candidates for general stress biomarkers.

\section{Acknowledgements}

The financial supports from FCT (Foundation for Science and Technology) provided through contract SFRH/BPD/26970/2006, by Centre for Marine and Environmental Research (CIMA) \& Technology and Sciences Faculty \& University of Algarve are gratefully acknowledged. Authors also acknowledge Dr. Caterina Oliveri for technical assistance in microarray hybridization analysis. The MYTARRAY slides were developed and printed by CRIBI BIOTECHNOLOGY CENTER - University of Padova (Italy).

\section{Appendix A. Supplementary data}

Supplementary data related to this article can be found at http:// dx.doi.org/10.1016/j.marenvres.2016.05.010.

\section{References}

Abbott, D.W., Yang, Y., Hutti, J.E., Madhavarapu, S., Kelliher, M.A., Cantley, L.C., 2007. Coordinated regulation of Toll-like receptor and NOD2 signaling by K63-linked polyubiquitin chains. Mol. Cell Biol. 27, 6012-6025.

Ashburner, M., Ball, C.A., Blake, J.A., Botstein, D., Butler, H., Cherry, J.M., Davis, A.P. Dolinski, K., Dwight, S.S., Eppig, J.T., Harris, M.A., Hill, D.P., Issel-Tarver, L., Kasarskis, A., Lewis, S., Matese, J.C., Richardson, J.E., Ringwald, M., Rubin, G.M., Sherlock, G., 2000. Gene ontology: tool for the unification of biology. Nat. Genet. 25, 25-29.

Badariotti, F., Thuau, R., Lelong, C., Dubos, M.P., Favrel, P., 2007. Characterization of an atypical family 18 chitinase from the oyster Crassostrea gigas: evidence for a role in early development and immunity. Dev. Comp. Immunol. 31, 559-570.

Banni, M., Negri, A., Mignone, F., Boussetta, H., Viarengo, A., et al., 2011. Gene expression rhythms in the mussel Mytilus galloprovincialis (Lam.) across an annual cycle. PLoS ONE 6 (5), e18904. http://dx.doi.org/10.1371/ journal.pone.0018904.

Banni, M., Negri, A., Rebelo, M., Rapallo, F., Boussetta, H., Viarengo, A., Dondero, F., 2009. Expression analysis of the molluscan p53 protein family mRNA in mussels (Mytilus spp.) exposed to organic contaminants. Comp. Biochem. Physiol. C Toxicol. Pharmacol. 149, 414-418. http://dx.doi.org/10.1016/j.cbpc.2008.09.017.

Bauernfeind, F.G., Horvath, G., Stutz, A., Alnemri, E.S., MacDonald, K., Speert, D., Fernandes-Alnemri, T., Wu, J., Monks, B.G., Fitzgerald, K.A., Hornung, V., Latz, E., 2009. Cutting edge: NF-kappaB activating pattern recognition and cytokine receptors license NLRP3 inflammasome activation by regulating NLRP3 expression. J. Immunol. 183, 787-791. http://dx.doi.org/10.4049/jimmunol.0901363.

Benjamini, Y., Hochberg, Y., 1995. Controlling the false discovery rate: a practical and powerful approach to multiple testing. J. R. Stat. Soc. Ser. B Methodol. 57 (1), 289-300.

Birkbecka, T.H., McHenery, J.G., 1984. Chitinase in the mussel, Mytilus edulis (L.). Comp. Biochem. Physiology Part B Comp. Biochem. 77 (4), 861-865.

Boatti, L., Boria, I., Cancio, I., Wenne, R., Lethonen, K., Vassilenko, E., Mignone, F., Dondero, F., 2012. Development of high-resolution arrays in Mytilus sp. for ecophysiological applications and toxicogenomics. Comp. Biochem. Physiology Part A Mol. Integr. Physiology 163, S49.

Bonelli, P., Tuccillo, F.M., Calemma, R., Pezzetti, F., Borrelli, A., Martinelli, R., De Rosa, A., Esposito, D., Palaia, R., Castello, G., 2011. Changes in the gene expression profile of gastric cancer cells in response to ibuprofen: a gene pathway analysis. Pharmacogenomics J. 11, 412-428.

Brown, M.P.S., Grundy, W.N., Lin, D., Cristianini, N., Sugnet, C.W., Furey, T.S., Ares, M., Haussler, D., 2000. Knowledge-based analysis of microarray gene expression data by using support vector machines. Proc. Natl. Acad. Sci. USA 97, 262-267.

Canesi, L., Betti, M., Ciacci, C., Lorusso, L.C., Pruzzo, C., Gallo, G., 2006. Cell signalling in the immune response of mussel hemocytes. Invertebr. Surviv. J. 3, 40-49.

Canesi, L., Negri, A., Barmo, C., Banni, M., Gallo, G., Viarengo, A., Dondero, F., 2011. The organophosphate Chlorpyrifos interferes with the responses to $17 \beta$-estradiol in the digestive gland of the marine mussel Mytilus galloprovincialis. PLoS One. 6 (5), e19803.

Cho, I.J., Lee, A.K., Lee, S.J., Lee, M.G., Kim, S.G., 2005. Repression by oxidative stress of iNOS and cytokine gene induction in macrophages results from AP-1 and NFkappaB inhibition mediated by B cell translocation gene-1 activation. Free 
Radic. Biol. Med. 39, 1523-1536.

Conesa, A., Götz, S., García-Gómez, J.M., Terol, J., Talón, M., et al., 2005. Blast2GO: a universal tool for annotation, visualization and analysis in functional genomics research. Bioinformatics 21, 3674-3686.

Contardo-Jara, V., Lorenz, C., Pflugmacher, S., Nützmann, G., Kloas, W., Wiegand, C., 2011. Exposure to human pharmaceuticals Carbamazepine. Ibuprofen Bezafibrate causes Mol. Eff. Dreissena polymorpha Aquatic Toxicol. 105, 428-437.

Cryer, B., Feldman, M., 1998. Cyclooxygenase-1 and cyclooxygenase-2 selectivity of widely used nonsteroidal anti-inflammatory drugs. Am. J. Med. 104, 413-421.

Davis, B.K., Wen, H., Ting, J.P., 2011. The inflammasome NLRs in immunity, inflammation, and associated diseases. Annu. Rev. Immunol. 29, 707-735. http:// dx.doi.org/10.1146/annurev-immunol-031210-101405.

Dey, A., Tergaonkar, V., Lane, D.P., 2008. Double-edged swords as cancer therapeutics: simultaneously targeting p53 and NF-kappaB pathways. Nat. Rev. Drug Discov. 7, 1031-1040. http://dx.doi.org/10.1038/nrd2759.

Dondero, F., Banni, M., Negri, A., Boatti, L., Dagnino, A., et al., 2011. Interactions of a pesticide/heavy metal mixture in marine bivalves: a transcriptomic assessment. BMC Genomics 12, 195. http://dx.doi.org/10.1186/1471-2164-12-195.

Dondero, Francesco, Calisi, Antonio, 2015. Evaluation of pollution effects in marine organisms: "old" and "new generation" biomarkers. In: Bastia, M. (Ed.), "Coastal Ecosystems: Experiences and Recommendations for Environmental Monitoring Programs. 2015. Nova Science Publishers, New York, ISBN 978-1-63482-189-6.

Dondero, F., Negri, A., Boatti, L., Marsano, F., Mignone, F., et al., 2010. Transcriptomic and proteomic effects of a neonicotinoid insecticide mixture in the marine mussel (Mytilus galloprovincialis Lam.). Sci. Total Environ. 408, 3775-3786.

Dondero, F., Piacentini, L., Banni, M., Rebelo, M., Burlando, B., et al., 2005. Quantitative PCR analysis of two molluscan metallothionein genes unveils differential expression and regulation. Gene 345, 259-270. http://dx.doi.org/10.1016/ j.gene.2004.11.031.

Ericson, H., Thorsen, G., Kumblad, L., 2010. Physiological effects of diclofenac, ibuprofen and propranolol on Baltic Sea blue mussels. Aquat. Toxicol. 99, 223-231.

Fabbri, R., Montagna, M., Balbi, T., Raffo, E., Palumbo, F., Canesi, L., 2014. Adaptation of the bivalve embryotoxicity assay for the high throughput screening of emerging contaminants in Mytilus galloprovincialis. Mar. Environ. Res. 99, 1-8. http://dx.doi.org/10.1016/j.marenvres.2014.05.007.

Ferrer, I., Ginebreda, A., Figueras, M., Olivella, L., Tirapu, L., Vilanova, M., Barceló, D., 2001. Determination of drugs in surface water and wastewater samples by liquid chromatography-mass spectrometry: methods and preliminary results including toxicity studies with Vibrio fischeri. J. Chromatogr. A 938 (1), 187-197.

Fent, K., Weston, A.A., Caminada, D., 2006. Ecotoxicology of human pharmaceuticals. Aquat. Toxicol. 76, 122-159.

Gasch, A.P., Spellman, P.T., Kao, C.M., Carmel-Harel, O., Eisen, M.B., et al., 2000. Genomic expression programs in the response of yeast cells to environmental changes. Mol. Biol. Cell 11, 4241-4257.

Gaw, S., Thomas, K.V., Hutchinson, T.H., 2014. Sources, impacts and trends of pharmaceuticals in the marine and coastal environment. Philos. Trans. R. Soc. B 369, 20130572.

Gorbi, S., Lamberti, C.V., Notti, A., Benedetti, M., Fattorini, D., Moltedo, G., Regoli, F., 2008. An ecotoxicological protocol with caged mussels, Mytilus galloprovincialis, for monitoring the impact of an offshore platform in the Adriatic sea. Mar. Environ. Res. 65 (1), 34-49.

Gonzalez-Rey, M., Bebianno, M.J., 2011. Non-steroidal anti-inflammatory drug (NSAID) Ibuprofen distresses antioxidant defense system in mussel Mytilus galloprovincialis gills. Aquat. Toxicol. 105, 264-269.

Gonzalez-Rey, M., Bebianno, M.J., 2012. Does non-steroidal anti-inflammatory (NSAID) Ibuprofen induces antioxidant stress and endocrine disruption in mussel Mytilus galloprovincialis? Environ. Toxicol. Pharmacol. 33, 361-371.

Heckmann, L.H., Sibly, R.M., Connon, R., Hooper, H.L., Hutchinson, T.H., Maund, S.J., Hill, C.J., Bouetard, A., Callaghan, A., 2008. Systems biology meets stress ecology: linking molecular and organismal stress responses in Daphnia magna. Genome Biol. 9, R40. http://dx.doi.org/10.1186/gb-2008-9-2-r40.

Herpers, B., Wink, S., Fredriksson, L., Di, Z., Hendriks, G., Vrieling, H., de Bont, H., van de Water, B., 2016. Activation of the Nrf2 response by intrinsic hepatotoxic drugs correlates with suppression of NF- $\kappa \mathrm{B}$ activation and sensitizes toward TNF $\alpha$-induced cytotoxicity. Arch. Toxicol. 90, 1163-1179. http://dx.doi.org/ 10.1007/s00204-015-1536-3.

John-Aryankalayil, M., Palayoor, S.T., Cerna, D., Falduto, M.T., Magnuson, S.R., Coleman, C.N., 2009. NS-398, ibuprofen, and cyclooxygenase-2 RNA interference produce significantly different gene expression profiles in prostate cancer cells. Mol. Cancer Ther. 8, 261-273.

Jozefczuk, S., Klie, S., Catchpole, G., Szymanski, J., Cuadros-Inostroza, A., et al., 2010. Metabolomic and transcriptomic stress response of Escherichia coli. Mol. Syst. Biol. 6, 364.

Karin, M., Greten, F.R., 2005. NF-кB: linking inflammation and immunity to cancer development and progression. Nat. Rev. Immunol. 5 (10), 749-759.

Kearney, M., Simpson, S.J., Raubenheimer, D., Helmuth, B., 2010. Modelling the ecological niche from functional traits. Philosophical Trans. R. Soc. Lond. B Biol. Sci. 365 (1557), 3469-3483.

Lakhani, S.A., Masud, A., Kuida, K., Porter Jr., G.A., Booth, C.J., Mehal, W.Z., Inayat, I., Flavell, R.A., 2006. Caspases 3 and 7: key mediators of mitochondrial events of apoptosis. Science 311 (5762), 847-851, 2006 Feb 10.

Lamkanfi, M., Kanneganti, T.-D., 2010. Caspase-7: a protease involved in apoptosis and inflammation. Int. J. Biochem. Cell Biol. 42 (1), 21-24. http://doi.org/10. 1016/j.biocel.2009.09.013.

Mahuran, D.J., 1998. Lipids and lipid metabolism. Biochimica Biophysica Acta 1393,
$1-18$.

Matozzo, V., Rova, S., Marin, M.G., 2012. The nonsteroidal anti-inflammatory drug, ibuprofen, affects the immune parameters in the clam Ruditapes philippinarum. Mar. Environ. Res. 79, 116-121.

Mestre, A.S., Pires, J., Nogueira, J.M.F., Carvalho, A.P., 2007. Activated carbons for the adsorption of ibuprofen. Carbon 45, 1979-1988.

Mezzelani, M., Gorbi, S., Da Ros, Z., Fattorini, D., d'Errico, G., Milan, M., Bargelloni, L., Regoli, F., 2016. Ecotoxicological potential of non-steroidal anti-inflammatory drugs (NSAIDs) in marine organisms: bioavailability, biomarkers and natural occurrence in Mytilus galloprovincialis. Mar. Environ. Res. http://dx.doi.org 10.1016/j.marenvres.2016.03.005, 2016 Mar 22. pii: S0141-1136(16)30030-7.

Milan, M., Ferraresso, S., Ciofi, C., Chelazzi, G., Carrer, C., Ferrari, G., Pavan, L., Patarnello, T., Bargelloni, L., 2013a. Exploring the effects of seasonality and chemical pollution on the hepatopancreas transcriptome of the Manila clam. Mol. Ecol. 2, 2157-2172. http://dx.doi.org/10.1111/mec.12257.

Milan, M., Pauletto, M., Patarnello, T., Bargelloni, L., Marin, M.G., Matozzo, V., 2013b. Gene transcription and biomarker responses in the clam Ruditapes philippinarum after exposure to ibuprofen. Aquat. Toxicol. 126, 17-29. http:// dx.doi.org/10.1016/j.aquatox.2012.10.007.

Montagnani, C., Kappler, C., Reichhart, J.M., Escoubas, J.M., 2004. Cg-Rel, the first Rel/NF- $\mathrm{KB}$ homolog characterized in a mollusk, the Pacific oyster Crassostrea gigas. FEBS Lett. 561 (1), 75-82.

Montagnani, C., Labreuche, Y., Escoubas, J.M., 2008. Cg-IкB, a new member of the IкB protein family characterized in the pacific oyster Crassostrea gigas. Dev. Comp. Immunol. 32 (3), 182-190.

Moreira, R., Pereiro, P., Canchaya, C., Posada, D., Figueras, A., Novoa, B., 2015. RNASeq in Mytilus galloprovincialis: comparative transcriptomics and expression profiles among different tissues. BMC genomics 16 (1), 1.

Muttray, A.F., Cox, R.L., Reinisch, C.L., Baldwin, S.A., 2007. Identification of DeltaN Isoform and Polyadenylation Site Choice Variants in Molluscan p63/p73-Like Homologues. Mar. Biotechnol. 9, 217-230.

Oeckinghaus, A., Hayden, M.S., Ghosh, S., 2011. Crosstalk in NF-кB signaling pathways. Nat. Immunol. 12 (695), 708.

Parolini, M., Binelli, A., Cogni, D., Riva, C., Provini, A., 2009. An in vitro biomarker approach for the evaluation of the ecotoxicity of non-steroidal anti-inflammatory drugs (NSAIDs). Toxicol In Vitro 23 (5), 935-942.

Parolini, M., Binelli, A., Provini, A., 2011a. Chronic effects induced by ibuprofen on the freshwater bivalve Dreissena polymorpha. Ecotoxicol. Environ. Saf. 74 (6), 1586-1594.

Parolini, M., Quinn, B., Binelli, A., Provini, A., 2011b. Cytotoxicity assessment of four pharmaceutical compounds on the zebra mussel (Dreissena polymorpha) haemocytes, gill and digestive gland primary cell cultures. Chemosphere 84 (1), $91-100$.

Pedrouzo, M., Reverté, S., Borrull, F., Pocurull, E., Marcé, R.M., 2007. Pharmaceutical determination in surface and wastewaters using high-performance liquid chromatography-(electrospray)-mass spectrometry. J. Sep. Sci. 30, 297-303.

Peng, C.Y., Manning, L., Albertson, R., Doe, C.Q., 2000 Nov 30. The tumoursuppressor genes $\operatorname{lgl}$ and $\mathrm{dlg}$ regulate basal protein targeting in Drosophila neuroblasts. Nature 408 (6812), 596-600.

Pfaffl, M.W., Horgan, G.W., Dempfle, L., 2002. Relative expression software tool (REST) for group-wise comparison and statistical analysis of relative expression results in real-time PCR. Nucleic Acids Res. 30, e36.

Pfaffl, M.W., 2001. A new mathematical model for relative quantification in realtime RT-PCR. Nucleic Acids Res. 29, e45.

Richardson, S.D., Ternes, T.A., 2005. Water Analysis: emerging contaminants and current issues. Anal. Chem. 200577 (12), 3807-3838. http://dx.doi.org/10.1021/ ac058022x.

Ritchie, M.E., Phipson, B., Wu, D., Hu, Y., Law, C.W., Shi, W., Smyth, G.K., 2015. Limma powers differential expression analyses for RNA-sequencing and microarray studies. Nucleic Acids Res. 43 (7), e47.

Scheuren, N., Bang, H., Munster, T., Brune, K., Pahl, A., 1998. 1998 Modulation of transcription factor NF-kB by enantiomers of the nonsteroidal drug ibuprofen. Br. J. Pharmacol. 123, 645-652.

Schneider, M., Zimmermann, A.G., Roberts, R.A., Zhang, L., Swanson, K.V., Wen, H. Davis, B.K., Allen, I.C., Holl, E.K., Ye, Z., Rahman, A.H., Conti, B.J., Eitas, T.K. Koller, B.H., Ting, J.P., 2012. The innate immune sensor NLRC3 attenuates Tolllike receptor signaling via modification of the signaling adaptor TRAF6 and transcription factor NF- $\kappa$ B. Nat. Immunol. 13, 823-831. http://dx.doi.org/ 10.1038/ni.2378.

Serrano, M.A.S., Gonzalez-Rey, M., Mattos, J.J., Flores-Nunes, F., Mello, A.C.P. Zacchi, F.L., Piazza, E., Siebert, M.N., Piazza, R.S., Alvarez-Muñoz, D., RodriguezMozaz, S., Barceló, D., Bebianno, M.J., Gomes, C.H.A.M., Melo, C.M.R. Bainy, A.C.D., 2015. Differential gene transcription, biochemical responses, and cytotoxicity assessment in Pacific oyster Crassostrea gigas exposed to ibuprofen. Environ. Sci. Pollut. Res. 22, 17375-17385.

Sokolova, I.M., 2009. Apoptosis in molluscan immune defense. Invertebr. Surviv. J. 6, 49-58.

Sturn, A., Quackenbush, J., Trajanoski, Z., 2002. Genesis: cluster analysis of microarray data. Bioinformatics 18, 207-208.

Supek, F., Bošnjak, M., Škunca, N., Šmuc, T., 2011. Revigo summarizes and visualizes long lists of gene ontology terms. PLoS ONE 6 (7), e21800. http://dx.doi.org/ 10.1371/journal.pone.0021800.

Tegeder, I., Niederberger, E., Israr, E., Guhring, H., Brune, K., Euchenhofer, C., Grosch, S., Geisslinger, G., 2001. Inhibition of NF-kappaB and AP-1 activation by R.- and S-flurbiprofen. FASEB J. 15, 2-4. 
Ternes, T.A., 1998. Occurrence of drugs in German sewage treatment plants and rivers. Wat Res. 12, 3245-3260.

Thomas, K.V., Hilton, M.J., 2004. The occurrence of selected human pharmaceutical compounds in UK estuaries. Mar. Pollut. Bull. 49, 436-444.

Venier, P., Pallavicini, A., De Nardi, B., Lanfranchi, G., 2003. Towards a catalogue of genes transcribed in multiple tissues of Mytilus galloprovincialis. Gene 314, 29-40.
Venier, P., De Pittà, C., Pallavicini, A., Marsano, F., Varotto, L., et al., 2006. Development of mussel mRNA profiling: can gene expression trends reveal coastal water pollution? Mutat. Res. 602, 121-134. http://dx.doi.org/10.1016/ j.mrfmmm.2006.08.007.

Waters, M.D., Fostel, J.M., 2004. Toxicogenomics and systems toxicology: aims and prospects. Nat. Rev. Genet. 5, 936-948. http://dx.doi.org/10.1038/nrg1493. 